\title{
Exploring co-creation in practical film education from primary school to postgraduate study: Theoretical and auto-ethnographic perspectives upon teaching film practice
}

\author{
Jamie Chambers* - Edinburgh College of Art, UK
}

\begin{abstract}
Considering the emergent discourses around film education, there has been little discussion to date of co-creation: that is, how student practical film work might be mediated by, collaborated upon, or even contributed to, by those teachers, instructors, lecturers and practitioners assisting them in the process. This study explores the thorny question of co-creation through a series of case studies, employing an auto-ethnographic approach to reflect upon first-hand experiences of film education at primary, secondary, undergraduate and postgraduate levels.
\end{abstract}

Keywords: co-creation; collaboration; multimodal; cinema; dialogical; Bergala

The figure of the film producer elicits a certain discordance with the manner in which film education discourses tend to be rehearsed. While there are exceptions, theorizations of film education - particularly at primary and secondary level - often articulate the underlying sense of an idealist, semi-emancipatory project aspiring to assist students in realizing and empowering their inner selves and authentic voices. Student film work in this context is frequently seen as 'an expression of self that helps to build confidence in the film-maker ... [articulating] a one-to-one correspondence between the film, the story it tells, and the person who made the film' (Rosenfeld Halverson et al., 2009: 37). As a practitioner interested in the progressive, utopian potential of film education, I have written in this register myself, arguing that there 'would seem to be a real correlation between a process [of film education] that attempts to help children realise aspects of their own "dialect" (in exploring their own issues and concerns through cinema) and a greater sense of self-efficacy' (Chambers, forthcoming).

The comparatively grubby, worldly figure of the producer seems at first somewhat unwelcome within such idealist approaches - an intrusion into the purity of student voice that is aspired to. Within wider Western film culture, the figures of director and producer are frequently positioned as a Manichaean binary, entangled in ongoing dialectical struggle between artistic and monetary conceptions of value. Pejorative caricatures of the producer frequently serve as a metonym for a negatively rendered 'industry', a figure impinging upon creative freedom to enforce the lesslofty concerns of logistics, markets and capital. Interestingly, in student film education projects focused upon practice, learners' film outputs are often rehearsed in a manner similar to that in which such theories of auteurship operate in wider Western film culture: frequently there is a sense that learners' films either do or should articulate an 'authentic voice', that learners have 'done everything themselves', and that the 
resulting films are 'all their own work'. A recent contribution to the Film Education Journal argued for:

the value of letting children and young people discover that art may be about oneself, that it can be intimate and personal, and that it allows us to speak about ourselves, sharing what excites us, what worries us and what surrounds us. (Aidelman and Collel, 2018: 159)

Another stated that 'the beauty of a project like Understanding Cinema is that it is led by the children themselves' (Donnelly et al., 2018: 71).

Here we can identify several parallel, intersecting discourses: of authorship, 'voice', identity, agency, self-efficacy and empowerment. Film education projects, particularly those at primary and secondary level, are frequently conceived and discussed through a focus upon participant identity: 'New media production is as much about producing identities and social spaces as it is about creating media' (Willett et al., 2005: 2); 'there seems to be little disagreement that participation in narrative-based media production activities supports identity development' (Rosenfeld Halverson et al., 2009: 23). With some exceptions (see discussion of the In Progress project in Rosenfeld Halverson et al., 2009), this focus upon identity and singular authorship tends to lead to an individualist emphasis that, as Alexis Gibbs (2018) recently remarked, is not always the most comfortable fit with the more collective environment of the classroom. In a manner similar to auteur theory, a worldly multiplicity of voices (or, recalling Bakhtin, a heteroglossia) is quietened to emphasize the single, singular authoring voice (or voices) of the student(s) from whom the work is seen to arise as a discrete utterance. Here, ironically, the recognizable structure of Bakhtin's heteroglossia - whereby an authoritative monoglossia silences subaltern heteroglossic resistance - could be seen to be inverted, with the voices of teachers and instructors discursively 'silenced' in order to emphasize student authorship.

Within ongoing attempts to enable and empower student film-makers, the rhetorical 'quietening' of authoritative adult voices involved in student film production is both inevitable and understandable, and it is certainly not my intention here to undermine the sincere, committed practice of progressive pedagogies. And yet, such discursive formations serve to limit and obfuscate discussions of what is actually happening in the interactions between student film-makers and their adult interlocutors during student film productions. Considering the emergent discourses around film education, there has been surprisingly little discussion to date of co-creation: how students' practical film work might be mediated by, collaborated upon, or even contributed to, by those teachers, instructors, lecturers and practitioners assisting them in the process. And - further - if we are willing to admit that co-creation happens (which, of course, it does), then there has been little discussion of how that happens and how it might happen better. In beginning to address this, the following discussion will attempt to remain alive to distinctions between the structures of pedagogy under consideration, and - in particular - where educational environments are more formal (including assessment) and less formal (such as the extracurricular setting of an afterschool film club).

Most film education discourses, perhaps inevitably, tend to frame student practical work as possessing a relative discreteness without significant permeability from adult influence. Where adult influence is acknowledged, it is frequently in pejorative terms, (for example, Buckingham, 2003: 33) as a contaminant or an epistemic imposition. As a film education practitioner myself, I have frequently experienced and seen other colleagues experiencing a sense of embarrassment or discomfort when referring to 
(or, more commonly, finding ways to avoid referring to) the creative contribution or mediation of adults in student film-making work. At a screening many years ago, I tried to congratulate the practitioner who had been involved in a short film made with children, only to be told defensively, 'the children did everything themselves!' Elsewhere, I have had the uncomfortable experience of seeing children praised for creative decisions that - within a complex production process - I had made myself. Sitting in a packed auditorium in Paris as part of the 'Le cinéma, cent ans de jeunesse' project of the Cinémathèque française, I watched awkwardly as my students were praised by French ciné-pedagogical theorist Alain Bergala for their sensitive, organic editing - in the knowledge that all editing had been done by me!

Within idealistic, emancipatory, quasi-auteurist conceptions of student film work, adult mediation and co-creation cannot escape a sense of polluting the purity of student authorship that is aspired to. In attempting to inaugurate a critical discussion of co-creation, I am not perversely trying to wrangle extra credit for film education practitioners, but rather hoping to illuminate the fascinating collaborative matrix that every film completed within an educational context represents. As detailed below, student film productions represent a complex, multimodal tapestry of decisions, some of which have indeed been made by 'the students themselves', alongside decisions made collaboratively or dialectically, and still further decisions made either explicitly or implicitly by supervising or senior adults in the process. This notion of teachers actively and creatively involved in student practical work may seem problematic. It would seem antithetical, for example, to core educational motivations for a primary school teacher to write part of a student's story for a creative writing assignment. What do students learn and what expressive agency are they able to develop if teachers do their work for them - whether or not it is assessed? Even more problematically, within a higher education setting, how is a student to be marked if a lecturer has had a collaborative role on his or her film - particularly if that lecturer themselves is marking the work? At what point do collaboration and co-creation become forms of plagiarism?

There have indeed been moments when, attending screenings of learner film productions, I have begun to feel uneasy about the level of teacher input seemingly evident within a film. I remember watching a film reportedly made by children at a European film education event that consisted of a highly complex, unbroken dolly shot that seemed unlikely to be either conceived or performed by the 8 year olds in the film. Yet, while it would seem that there is a point at which the input of a film education practitioner can move beyond the organic, expectable level of co-creation to assume too much of the authoring force within a film, equally it would seem very difficult to identify exactly where that point is. While it might seem possible in a relatively abstracted theoretical context to cleanly delineate the productive activity and agency of the student from any 'contamination' from the co-authoring influence of the teacher, keeping the two separate in the worldly, contingent context of any educational encounter seems significantly more difficult. Consider: I am supervising a student's written master's degree dissertation essay and advise my student to explore Foucault, pointing them to a specific page or chapter, believing it will help them strengthen a particular aspect of their argument. Following my advice, the student does cite a passage of Foucault that I have pointed him or her towards, and this subsequently informs the way I mark the work - is this, too, not a form of co-creation? 
While there have been some brief mentions of a co-creative approach within the early issues of the Film Education Journal (see the 'shared responsibility for aesthetic decisions' between learners and instructing film-makers at the KurzFilmSchule in Bachmann and Zahn (2018: 87), or the learning structures requiring 'teachers to change their perspective on their own condition or role' in order to learn alongside students, 'discovering at the same time as them' (Aidelman and Collel, 2018: 153)), discussions have tended to shy away from concrete descriptions of what such cocreative approaches might look like. That a healthy discursive approach to co-creation is yet to emerge perhaps reflects an inevitable, ongoing discomfort within critical pedagogies with the authority of the teacher, and the dissonance between senior authority (not, indeed, dissimilar to that of the producer) and ideals of student voice, autonomy and self-efficacy. Such is the discomfort in rehearsing teacherly authority that idealistic discussions of 'voice' have themselves been troubled by critics suspicious of the manner in which student voice may be ventriloquized or interpellated by teachers as a form of command performance. Mimi Orner (1992: 75) finds that 'liberatory', 'emancipatory' 'demands for student voice ... presuppose subject positions for teachers and students which are highly problematic': 'Student voice, as it has been conceptualized in work which claims to empower students, is an oppressive construct - one that ... perpetuates relations of domination in the name of liberation.' As Orner identifies - and as I have discussed elsewhere (Chambers, forthcoming) - students and youth are often positioned as Other (Orner, 1992: 76) in pedagogical discourses, situated in relation to the teacher as source of power, control and authority. As has been argued within media studies discourses, teachers must thus attempt to eschew their own tastes and opinions in order to avoid the paternalistic dangers of epistemic imposition. David Buckingham (2003: 33) argues that:

teacherly attempts at imposing cultural, moral or political authority children experience in their daily lives are very unlikely to be taken seriously. If, as in many cases, they are based on a paternalistic contempt for children's tastes and pleasures, they certainly deserve to be rejected.

I would argue that attempts to rehearse the non-interventionist, non-impositional teacher verge upon the disingenuous: how can any programme of education avoid some sense of epistemic imposition? How can any given teacher suppress his or her worldly credentials as a historical subject? Alain Bergala's more partial, worldly, implicated figure of the passeur (as discussed in the inaugural issue of the Film Education Journal (Burn, 2018; Chambers, 2018; Gibbs, 2018; Henzler, 2018)) is perhaps a more convincing model for the practical film educator, as discussed below. Further, rehearsals of the non-interventionist teacher risk an abdication of responsibility, suggesting that one can avoid the realities of teacherly authority through reflexive intellectual gymnastics. As this essay will go on to discuss, pejorative caricatures of teacherly authority also serve as a hindrance to looking at what actually happens within creative processes in class, and this would seem a key reason why healthy discourses around co-creation and collaboration in practical learning have yet to arise.

As I have mentioned above, it is unequivocally not my intention here to attack the worthy idealism of progressive film education projects, nor to undermine the laudable efforts of film education practitioners to create spaces for students of all ages to articulate their own particular aesthetic visions as free as possible from the paternalist impositions of educational authority, as I have celebrated elsewhere (Chambers, 2018). 
Nonetheless, working both in the abstracted domain of pedagogical theory and 'on the ground' in classrooms, I am increasingly interested by the manner in which the idealistic discourses of film education map on to the more contingent, worldly practices taking place in diverse education environments in primary, secondary and higher education. At times it would seem essential elements of practice risk being obfuscated and rendered invisible if they happen to take place in the shadow of the worthy ideological tenets and assumptions of progressive pedagogical discourses. The central consideration of this essay is to begin an exploration of co-creation, which risks being one of the key 'elephants in the room' in the discourses surrounding practical film education. In discussing a series of short case studies drawn from my own experiences, I will attempt a broad survey of co-creation across learner film-making projects with which I have been involved, from primary and secondary schools to lecturing at undergraduate and postgraduate level, while drawing on an autobiographical account of my own experience of practical film education as a student at the London Film School. Given the relative dearth of theoretical discussions of co-creation to date, I present this discussion more as an auto-ethnographic reflection upon my own parallel experiences as a film student, film-maker, and now film education practitioner. In advocating for the shedding of light upon co-creation, I hope that my intervention is able, to some extent, to rise to Orner's (1992: 88) still-resonant challenge that 'the time has come to listen to those who have been asking others to speak'. Considering elsewhere how student voice might be approached within practical programmes of film education such as Understanding Cinema, I asked:

what affordances are opened up for children when an idea of 'authentic voice' is pursued pragmatically? As an unworldly ideal, the notion of 'authentic voice' would seem ultimately unachievable. Yet what happens if that impossibility is both accepted and ignored, and a child's 'authentic voice' is viewed as a sort of unreachable destination - a goal that can be strived towards, if not arrived at? Where do we find ourselves if we embark towards such utopian coordinates? (Chambers, forthcoming)

It would now seem important to look at the practical, worldly realities arising from situations where student voice is being pursued, in order to think about how student voice may be pursued better. Ultimately, in beginning to explore worldly practices of co-creation, I have found that the figure of the film producer becomes again an unexpected ally in navigating towards an early model of co-creation in practical film education.

\section{The creative producer as a model of co-creation: An autobiographical approach}

In The Cinema Hypothesis, Alain Bergala (2016) presents the passeur as a film educator shaped by their own personal encounters with film, a figure defined by their own partiality and autobiography:

When an adult voluntarily takes the risk, whether by conviction or by personal love of an art, to become a 'messenger', his own symbolic status changes, he abandons for a moment his role as an educator, as that role has been defined and delimited by the institution, in order to take up a way of speaking with and interacting with his students that is rooted in a different part of himself, more vulnerable, where his personal tastes come 
into play, as well as his more intimate relationship to one work of art or another, where the 'I' that can be so harmful in the role of the teacher becomes practically indispensable to a good initiation. (Bergala, 2016: 38-9, italics mine)

In exploring the model of co-creation that I have come to follow in my own practical film teaching, I wish to offer a gloss on Bergala's autobiographical conception of the passeur. Documenting his own, personal discovery of cinema during an 'awkward and anxious childhood' (ibid.: 12), Bergala positions the film education practitioner as a partial, worldly individual shaped by particular personal experiences and encounters with film. Expanding this act of chronicling beyond encounters with film itself, I here discuss encounters with film education, and how such encounters have subsequently shaped my approach as a film education practitioner.

I was not fortunate enough to receive any form of film education at either primary or secondary school. At a state primary school in Edinburgh, my memories of film in the classroom are as either a treat or a distraction: we would frequently sit together on the carpet in the last, excitable days of the winter or summer term to watch Santa Claus: The Movie (1985) or The Borrowers (1997) while our teacher did other things. Later, at a small, specialist music secondary school, media education was not an option within a limited academic curriculum, and film appeared in our classrooms only in an instrumentalized register in the service of other subjects. When studying French, we would watch Au revoir les enfants (1987) or Jean de Florette (1986), studying English, Twelfth Night (1996) or Hamlet (1996), studying history, Rasputin (1996), and so forth. My own discovery of cinema on both a theoretical and a practical level was therefore, in a manner recalling Bergala (2016) and Pinkerton (2017), relatively private, personal and individualist. My family did not have a television, and thus screen storytelling took on the cast of a forbidden pleasure, all the more desirable for its relative absence in my daily life. In my teens, I began to make short pastiches of popular cinema using a neighbour's video camera, a productive three-year run that came to an abrupt end (along with my neighbour's video camera) after an unsuccessful stunt driving a bicycle off a high garden wall. Alongside my enthusiastic practical work, I became a regular cinema-goer - with my friends, with my grandmother and increasingly on my own - attending the wealth of film festivals taking place in Edinburgh. Through these experiences, I began to develop a sense of my own taste, and an appreciation for the films of particular film-makers such Robert Altman, Bong Joon-ho, Luis Buñuel, Souleymane Cissé, Jane Campion, David Lynch and Abderrahmane Sissako. My amateur productions continued during my time at university, where, during a degree in musicology, I was finally able to afford to buy my first video camera, which I used to shoot a feature-length, Altman-inspired drama exploring the interlinking lives of conceptual artists.

By the time I reached my first formal experience of film education at the London Film School (at the age of 23), I had developed a significant sense of personal autonomy in my approach to cinema on both a practical and a theoretical level. While, up to that point, film-making had always been a social enterprise involving multiple collaborators upon whom my films were dependent to varying extents, the primary authorship of my work remained relatively untroubled. While I may have debated aspects of the creative process with my collaborators, the amateur, non-institutional nature of my productions meant that I was ultimately answerable only to myself. This relatively untroubled individualist paradigm of film-making changed dramatically at the London Film School (LFS), where I was introduced - for the first time - to the 
disquieting experience of pitching ideas not just to opinionated, experienced peers but also to authoritative teachers who frequently found my work wanting, insufficient or plain bad. Throughout my two years on the non-specializing MA in film-making at the LFS, we continually submitted work for comment, initially at script level, and subsequently as rushes, rough assemblies, final cuts, and at a series of discomfiting 'crit' sessions at the end of each term where our work was critiqued by assembled staff and visiting industry professionals. Our work was judged and commented upon constantly, subjected to an unruly array of perspectives, whether we wanted them or not. The rationale, we were told, was that this was what industry was like: individual work opened up again and again to criticism as part of an intensely social, collective process of collaboration concluding (hopefully!) in contact with outside, public audiences. While there remained, in the school's approach, a central sense of auteurship and the creative prerogative of the director, this was situated within a profoundly discursive, dialogical and even dialectical process.

Attempting to take a summative perspective upon the practice of film-making, it would seem always to be a dialogical process involving a broad spectrum of interlocutors, some of them 'junior' and some of them 'senior'. While 'the auteur' may have the ability to articulate a sense of a distinctive, personal voice, they do so - and this applies to even the most senior film-makers - amid a considerable degree of input, suggestion, collaboration and co-creation with other voices in the process. Richard Linklater once remarked that having 'final cut' (the ability, for a director, to choose the final version of the film) meant that he listened much more carefully to other people's suggestions. Why, then, should we expect children's or older students' film-making projects to be any different? As a craft, film-making can take years, or indeed a lifetime, to master merely one discipline, be it cinematography, editing or direction. In this respect, compared with other creative media, film-making projects are peculiar for their pronounced multimodality: the production of almost any film requires the convergence of multiple crafts - camera work, direction, editing, sound and (in the case of drama) script and acting. By comparison, an act of creative writing is relatively monomodal, taking considerably less time and fewer resources to oversee from an educational perspective. Where an essay, relatively speaking, requires one craft and one author, to make a film takes many. Given this multimodality there are an enormous number of decisions required in the production of any fully realized film, and it is frequently the case - even in professional productions - that certain aesthetic decisions simply go unmade. Alan Bernstein, then the Head of Studies at LFS, remarked to me that each director needs to decide the parameters within which she or he is going to make decisions, and those they are going to leave either to other members of their crew-or indeed to chance. The potential for aesthetic decisions within any production is limitless, and while certain directors may have a keen eye for production design, camera movement and composition, others may focus on performance and pacing, leaving such visual parameters to their cinematographer, or leaving them relatively unexplored. If then, we would not expect the world's most celebrated film-makers to realize their auteurist visions and authentic voices outside a complex, collaborative, multimodal process, is it not somewhat absurd to have different expectations of student film productions?

As I moved up the London Film School, I began to develop more in-depth relationships with particular members of staff. A largely voluntary process, this involved a high degree of self-efficacy, similar to seeking out collaborators. I listened to particular types of feedback from particular members of staff, and actively chose those 
who I wished to have a formative influence on my film. Towards the end of my time at the LFS, I made the relatively conscious decision to work with a particular member of staff who went on to play a highly significant role in shepherding the two films I made in my graduation term. This person took on a mentorship role in my work that went far beyond what I had previously thought of as 'teaching', and that now seems to be better described as co-creation. My gratitude to this member of staff is enormous; I leave them anonymous here as I suspect they would find it embarrassing to be so singled out. This member of staff provided an ongoing commentary on a series of over ten subsequent drafts of the script for my graduation film. At times this feedback was provided within regular tutorial sessions within the school day, but at other times it was provided at weekends or relayed in phone calls at 9 p.m. This person's influence on my script was enormous: whole plotlines and characters were taken out following their advice, and additional elements were added. Their influence helped to define the tone, style and shape of the film we went on to shoot, and ultimately I explicitly sought a green light from them before I considered the script finished. At a certain point in the process, this member of staff - believing strongly in the potential of the film I was making - made a significant intervention to ensure the film was shot on a RED camera rather than the Sony EX1 we were intending to use, a decision that would subsequently have a significant effect upon the fortunes of the film on the festival and distribution circuits. When the shoot was finished, this member of staff watched versions of the cut, chaired audience screenings, and, at a formative juncture, even presided over a cut of the film without my input.

My experience working with this member of staff redefined what I had previously thought of as teaching: they exercised a decisive, shaping influence on my work, giving their own time, personal energies and ideas to my film work well beyond what seemed required of them as a 'teacher'. In these terms, it would seem more fitting to see them as a co-creator or collaborator. I learnt from them but, recalling Bergala's passeur, I also learnt through them, watching them work and considering creative decisions that they made. Sometimes the learning would take months and even years of reflection to fully process, and yet it has - for me - had an enormous legacy, both for my work as a film-maker and as a film education practitioner. In this respect, their teaching approach recalls Vygotsky's (1978: 102) 'zones of proximal development', and in particular the notion that 'play creates a zone of proximal development of the child. In play a child always behaves beyond his average age, above his daily behavior; in play it is as though he were a head taller than himself.' Looking here to present one possible model of cocreation for film education practitioners involved in learner film-making, I return to the figure of the producer. The director of the London Film School while I was a student was Ben Gibson, a producer who previously served as the Head of Production at the British Film Institute from 1989 to 1997. It is perhaps unsurprising that the LFS would then promote the notion of a 'creative producer' as a shaper, collaborator and cocreator, an active creative agent rather than a mere enabler in charge of budget and logistics.

In the final section of this essay, I reflect upon a series of case studies of my own experiences working on learner film productions from primary to postgraduate level. In reflecting upon these experiences alongside my own experiences of film education at the London Film School, I am struck by the parallel proximities of the film education practitioner - enabling, nurturing and co-creating student film projects - and the role of the creative producer. As I will argue, drawing comparisons between creative producers and film education practitioners allows us to see learner film-making as a continuum 
within film culture, whereby at each successive step towards greater autonomy, each production remains dialogical and co-creative, the product of multiple interlocutors, some junior and some senior. In trying to draw links between practices at different points upon that continuum, I hope both to demystify and destigmatize the process of co-creation and - while preserving the corrective placed upon 'authentic student voice' - begin a discussion of the worldlier practices underlying it. In doing so, I am strengthened in my convictions by the cine-pedagogy of Alain Bergala (2016), which similarly situates un-dumbed-down, non-exceptionalist learner film-making practices within an ongoing, broader tradition of world film culture

\section{Co-creation in context: Primary, secondary, undergraduate and postgraduate learner film projects}

Reflecting globally across my experiences assisting learner film productions, I am struck overall by the strong similarities in my approach, whether I am working with 8-yearold primary school children or 30-year-old postgraduate students. Considering this spectrum of teaching environments through the prism of film education practitioner as creative producer, one can begin to make the case for a relatively unbroken continuum of practice within film culture whereby film-making remains at all times dialogical - a dialectic between a designated authoring voice (or voices) and the other interlocutors (both junior and senior) involved in the process. As Bakhtin (1990: 26) remarks:

the living utterance, having taken meaning and shape at a particular historical moment in a socially specific environment, cannot fail to brush up against thousands of living dialogic threads, woven by socio-ideological consciousness around the given object of an utterance; it cannot fail to become an active participant in social dialogue. After all, the utterance arises out of this dialogue as a continuation of it and as a rejoinder to it.

Bakthin was primarily concerned with the relatively monomodal form of the novel, rather than the highly collaborative, co-creative medium of cinema, and thus similar should be said of any film made in or outside an educational context.

Despite broad continuities, there are, however, a number of identifiable factors determining the degree of co-creational input I have had as a film education practitioner in different educational contexts, the most significant being the relative autonomy of my students. As is self-evident, I would expect to have less tangible, 'hands-on' input to a postgraduate student film production than that of a primary school student, and would expect the former to have a significantly greater degree of agency in the production process. While a degree of co-creation is present throughout, arguably the greater hands-on agency and autonomy attributed to the student within the production process, the lesser agency I have myself as a film educator within the process. In children's film productions (where, normatively, film work is not marked), I have greater agency to intervene as I see fit in the best interests of the project, whereas in an undergraduate project, it would be inappropriate or nonsensical for me to take on a film's editing myself if a student runs out of time. With children's film-making work in particular, I feel it is my responsibility to open up as many possible aspects of the creative process of a film production to participants, while intervening to prop up other aspects of the production myself when there is insufficient time. I attempt to give students a sense of the significance of the different aesthetic choices available to them, and subsequently the space to make those 
choices themselves, and if there is simply not time to make certain choices, then I make them myself.

As this suggests, another crucial aspect determining my co-creative input to a project is the affordances and logistical concerns arising from any given educational context. Each film education project has a particular logistical structure - or, to recall Bachmann and Zahn (2018) - an ecology shaped by institutional affordances, project structure, the dispositions of the students (including their age, ability to concentrate and ability to work in particular groups), the disposition of the teacher, the availability (and functionality) of equipment and so on. All of these factors conspire to generate a global level of affordance that, in turn, determines how much of the complex, multimodal process of film production I am able to open up to students. While the ideal is indeed that students 'do everything themselves', in projects where I am working with young children in particular, I will frequently intervene to prop up parts of the creative process that there is not sufficient time to cover. Frequently, this is the edit, for which (as a complex, technical task occurring late in the production process) we often run out of time. At times, I have served as a camera operator, and at times even something resembling a director, allowing children's expressive agencies to be situated more within the modes of performance, script and an overriding vision for the film. In comparison, in undergraduate or postgraduate contexts (and particularly where a film is being marked), I have less active, productive agency within the creative process, and in these cases my input is usually limited to optional verbal advice - although, as I shall go on to detail, this verbal advice can still exert a significant formative influence on the film. Depending on the age and agency of the students, and the pedagogical environment and approach, certain parts of the creative process (or, indeed, 'modes' of the films) will be demarcated with differing degrees of permeability as being the expressive domain of the students, while others - such as the initial brief, the script development process and the edit - tend to remain more permeable to my input as a co-creator.

In what follows, I will survey a series of case studies endeavouring to chart some of the differing forms that co-creation can take in learner film-making projects at different points in a life cycle of film education. All the examples of primary and secondary film education are drawn from my work with Understanding Cinema, a Scottish film education project in state school classrooms based on the 'Le cinéma, cent ans de jeunesse' project of the Cinémathèque française. Where appropriate, I have included links to watch the films being discussed.

\section{Blue Raspberry (primary school)}

In 2013/14, I was working in Law Primary School in East Lothian with a P5 (9-10 years old) class of approximately thirty children. The class teacher was notably supportive and well organized, and this served to significantly enable what was possible for the children's film productions. Early in the year, I challenged the children to each shoot a 'Lumière minute', a one-minute short documentary from a static camera perspective documenting an aspect of his or her life (Chambers, forthcoming). Many of the children used the Lumière minute to serve a diaristic function, documenting a series of different facets of their day. Notably, Law Primary School was located within a relatively privileged, middle-class area of East Lothian, and here students were allowed to take the cameras home, unlike other schools with which I have worked, which unfortunately did not feel as confident allowing children to take equipment home. This afforded student film-makers at Law a considerable degree of agency outside the classroom, 
which then opened up considerable scope for the film that became Blue Raspberry (vimeo.com/100150741; see Figure 1).

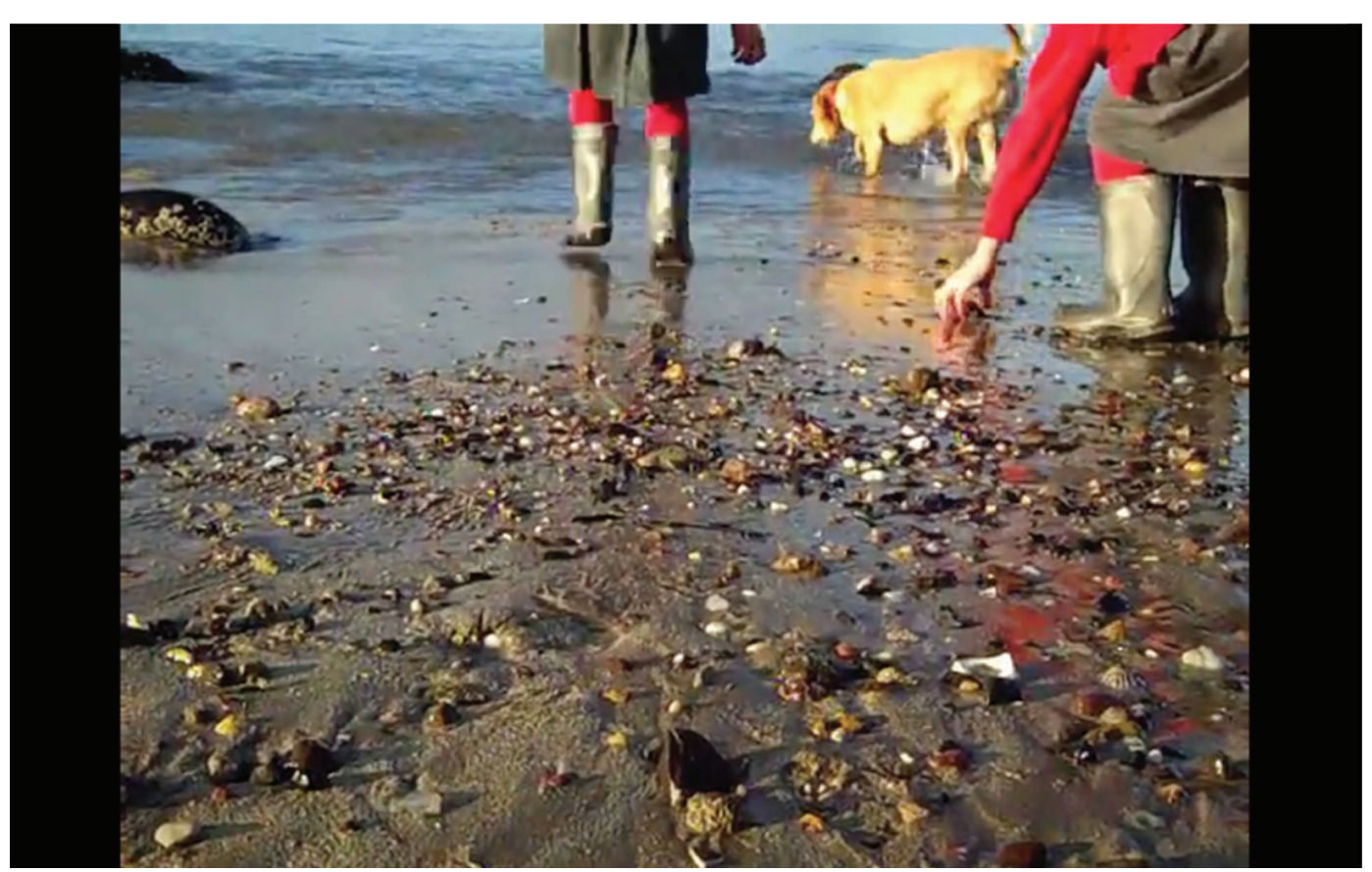

Figure 1: Elided frames in Blue Raspberry

Bridget Harley's work for the Lumière minute exercise was exceptional in terms of both quantity (Bridget took the camera home several times, and would often shoot more than forty Lumière minutes per day) and quality, in terms of her accomplished composition and inquisitive, elliptical framings. Sensing considerable potential in Bridget's work (and a notable degree of parental support), and feeling that - as a shy student - Bridget might be better working on her own, I devised a separate project whereby she could work independently on her own film while other children in the class were working in groups. Working thus in a manner not dissimilar to a 'creative producer', I also took on the role of Bridget's script consultant and editor. I selected a series of what I felt were Bridget's best Lumière minutes and suggested that she come up with a short, naturalistic narrative we might intercut between them. Without my input (although perhaps with some input from her parents), Bridget conceived of a narrative whereby she, playing a version of herself, covets some lurid blue sweets in the local sweet shop that she buys against the wishes of her parents, only to be subsequently caught blue-tongued. Latterly in the shooting process, I watched Bridget's rushes week to week, and in places challenged her to shoot particular scenes or shots again depending on their clarity and legibility: sometimes a key piece of dialogue could not be heard, or separate shots would cut together awkwardly, and I asked Bridget to try shooting them again. Finally, running short on time, I edited the film myself at home and showed Bridget two subsequent cuts, with both of which she seemed happy. The film was praised highly by many of the adults attending its screening at the 2014 Edinburgh International Film Festival (EIFF), and Bridget was described as 'a genius' by a member of the Cinémathèque française, who singled out her framings (an aspect of the filming for which I had had no direct input) as one of the key achievements of the film. 
Interestingly, it would seem easy to fall into a defensive register when considering the input I had in Bridget's film. I find myself feeling compelled to shroud or diminish my own influence with the film in furthering a sense of sole authorship or auteurship for Bridget. Within the wider context of this argument, however, such defensiveness seems neither necessary nor sensical. As a film education practitioner, I was able to open certain parameters of the film-making process to Bridget (the entirety of the shoot, which happened outside school, without input from me, and the scripting process), while being obliged to perform other aspects myself (such as the editing) due to the time constraints of the project. As a creative producer and editor, I had a strong shaping influence on the film, particularly during the edit, my feedback to rushes and script development. While I made a significant contribution to the film, however, my input does nothing to obscure Bridget's considerable achievement, or the presence of her voice in the film. Were Bridget a professional film director, the idea that she would produce a film of the standard of Blue Raspberry without the additional input of an editor or producer would be absurd. Why should it be any different because she was (then) at primary school?

\section{Yes Sir (secondary school)}

Two years later, during Understanding Cinema 2015/16, I found myself working at the Wester Hailes Education Centre in North Edinburgh with an S4 class (15-16 years old). Wester Hailes is a relatively underprivileged area of Edinburgh, ranking high on the Scottish Index of Multiple Deprivation. The class with which I was working contained a number of children with behavioural difficulties and truancy issues, and it was hoped that a programme of film education, exploring popular forms and non-traditional literacies, might engage the students. While the attendance of the class became somewhat intermittent throughout the year (their teacher described them to me as frequently 'voting with their feet'), the class managed to produce two impressive ten-minute films. The first of these - Yes Sir (vimeo.com/169730286) - was particularly significant given that the film's director, Demmie, was also a member of Edinburgh Education Authority's Young Mums' programme - a source of childcare support allowing high-school students to continue their education. Demmie lived in a far-removed part of Edinburgh around 12 miles away from the school, providing yet another obstacle for her to attend classes. Demonstrating considerable vision and commitment, however, she overcame these obstacles to shoot an accomplished short film exploring questions of truancy relevant for many of the students in her class. Given the relative age and independence of the students, the large part of the shoot was conducted without adult influence, with a few small exceptions: towards the end of the shoot, we found we were missing two remaining scenes and, given Demmie's absence on a particular day, I shot the reverse angles of the film's protagonist being confronted by a teacher in the corridor (towards the end of the film), and the final encounter with his friend where he decides not to play truant again. The rest of the material for Yes Sir was shot either by the director herself, or by other members of the group without any direct adult intervention. This included some of the most accomplished moments of the film (such as the powerful opening scene, a long take in which the protagonist and his friend are given a brutal dressing-down by their head teacher; see Figure 2). 


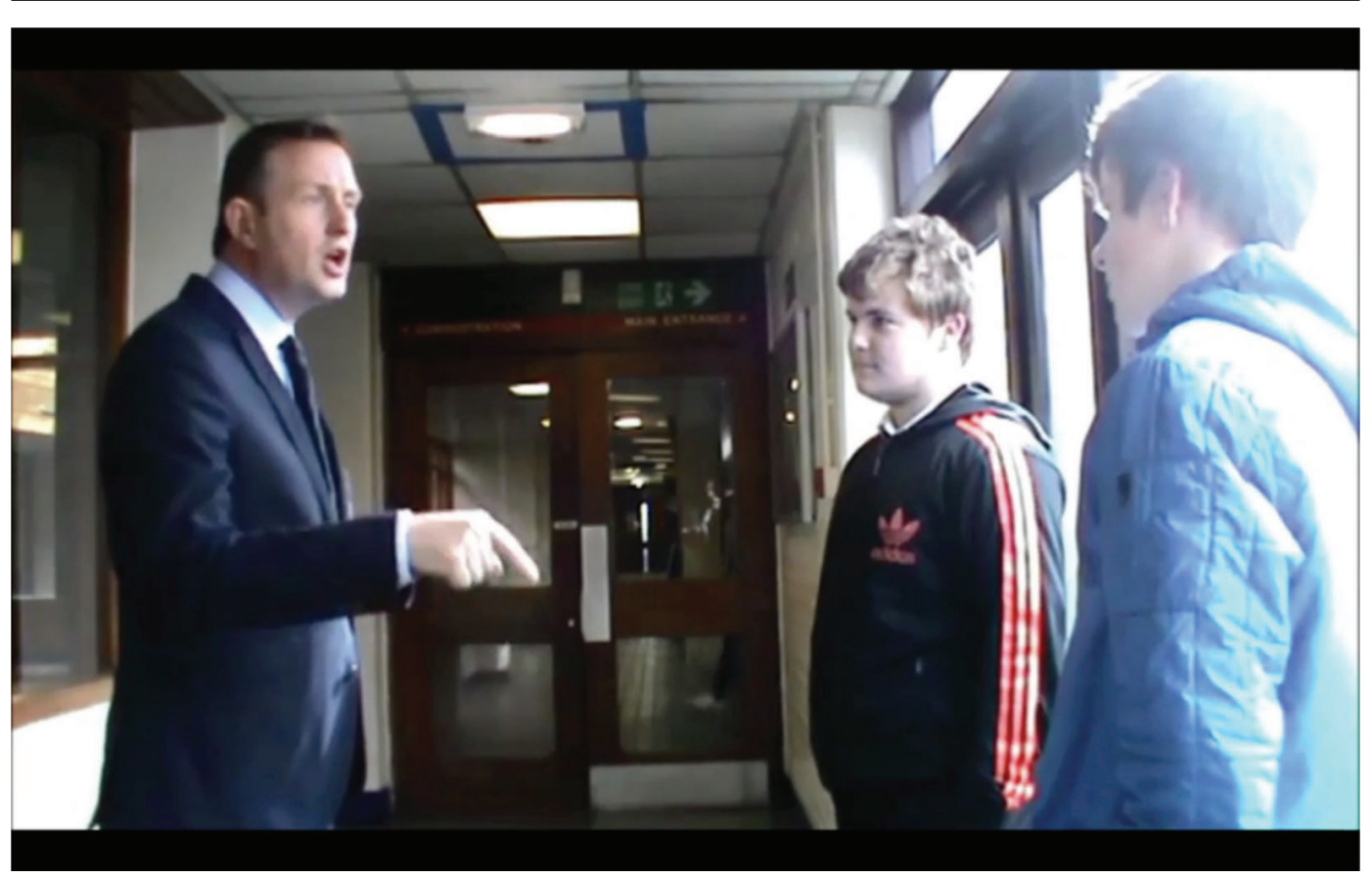

Figure 2: A hard lesson in Yes Sir

The editing process for Yes Sir was initially led by Demmie, who performed a rough assembly of the film on Windows Movie Maker. Latterly, as time began to run out and the deadline for the films to be submitted to EIFF began to loom, I started to take a more active role in the editing process in order to allow the group to be out shooting while I was editing. (In accordance with the school day, I worked in short, 45-minute sessions with the students, who would not always turn up on time.) While Demmie began the edit, we latterly adopted an approach whereby I would show her and her group subsequent cuts for their approval. An area of the edit where I had some influence was the use of atmospheric, ambient close-ups, such as the shots of seagulls, of the feather and of the sky. These shots were part of an earlier Understanding Cinema exercise where the students shot short, haptic montages of weather conditions around their school, and had therefore been shot not only by Demmie's group but also by other classmates. During a session in which neither Demmie nor any of her collaborators were present, I edited a series of these shots into the film, in order to ensure the film met Understanding Cinema's 2015/16 brief of using weather as an expressive device (an element not legibly present in the film otherwise), and also to include the sense of a contribution from the wider class when the film (the only one from Wester Hailes Education Centre) was screened at EIFF. Reviewing the cut of the film in which I had inserted these close-ups a week later, Demmie and another of her collaborators expressed scepticism about the shots, seeming to indicate that they felt them to be pretentious and unnecessary. Grudgingly, however, they allowed themselves to be persuaded to leave them in. Notably, the students as a whole found it difficult to engage with Understanding Cinema's theme of weather, or 'le climat', which they seemed to find uninspiring and overly conceptual, preferring instead to focus on stories arising from the relative urgency of their own experience. This 'weather' element of the film was thus shoehorned in awkwardly by me in the latter stages of the film's production in a manner that seems questionable in retrospect, and may be undermining of the students' authorship of the film. In terms of my co-creative editor-director relationship 
with Demmie, the weather shots represented a moment in the film-making process in which my authority as a supervising adult bled into an otherwise constructive collaboration to impose aesthetic concerns from a position relatively removed from the student's experience of the film. While Yes Sir subsequently fitted the project brief, it contains a discordance between the dramatic footage shot by the students (the main body of the film), and the more lyrical, weather-based footage that I subsequently crowbarred into it - a decision that I now regret.

\section{Not Going Anywhere (primary school)}

During Understanding Cinema the following year, I found myself working for the first time at Lorne Primary School in Leith, with a small, relatively mature and focused P7 (11-12 years old) class. Reflecting the theme of Understanding Cinema 2016/17, 'le jeu', the students were tasked to make a film exploring a sense of 'play'. Two students in the class - Josh and Ryan - emerged from early exploratory exercises as a strong, on-screen double act, capable of conveying humour and pathos. Early in the year, I encouraged Josh and Ryan and their regular collaborators to conceive a narrative allowing them to explore both the humorous and dramatic elements of their double act. Working within their group, the pair conceived a story where, experiencing problems at home, Josh is led astray by bad influences. Although Ryan is initially able to connect with Josh, particularly when the two play together with a skateboard, the darkness in Josh's life ultimately overwhelms Ryan's attempts to get him back on track. The story seemed to draw on certain autobiographical aspects of the students' experience and, in places, to possess the smarting feel of lived experience. The film was shot entirely without my input, and one scene in particular - the long take in which Ryan tries to ask Josh if he is OK - was shot by the boys themselves, completely on their own initiative at home, using a parent's camera.

Not Going Anywhere (youtube.com/watch?v=vBWmw7FDd0s) is significant among the learner film productions discussed here as it was edited almost entirely by the students themselves. Considering the discussion of media-ecological project affordances above, Josh and Ryan's class were focused, mature and under the supervision of an experienced, committed and well-organized teacher who was able to open up a great deal of shooting time in between the weekly sessions when I saw the class. As a result, the group were well on schedule and able to undertake much of the edit themselves. Arooba, an accomplished student who presided over much of the film's direction, undertook an ongoing, cumulative edit on Windows Movie Maker over the six weeks during which the film was shot, allowing the group to see what they still had to shoot, what aspects of the film were working and what might need to be reshot. An interesting complication arose later in the process, however: as the film was going to be screened at the Understanding Cinema screenings at EIFF 2017, it required a relatively professional export as an Apple Pro Res $\mathrm{HQ}$ that the simplistic affordances of Windows Movie Maker would not allow. I was thus required to painstakingly recreate Arooba's edit in Final Cut from the group's raw material, cut for cut. While doing so, I made a number of small changes to particular cuts in order to smooth out transitions and actions, shortening some shots and extending others. In particular, I chose to extend the film's powerful final shot of Josh and Reilly walking into a verdant green park (see Figure 3). I felt that the shot possessed considerable power, contrasting Josh's bleak predicament with the idyllic, sunny environs of the park, and thus felt it should last as long as the group's coverage allowed. Notably, I performed the edit two days before the EIFF deadline, and therefore did not have time to run these small changes by the students, who saw them for the first time on the screen. 


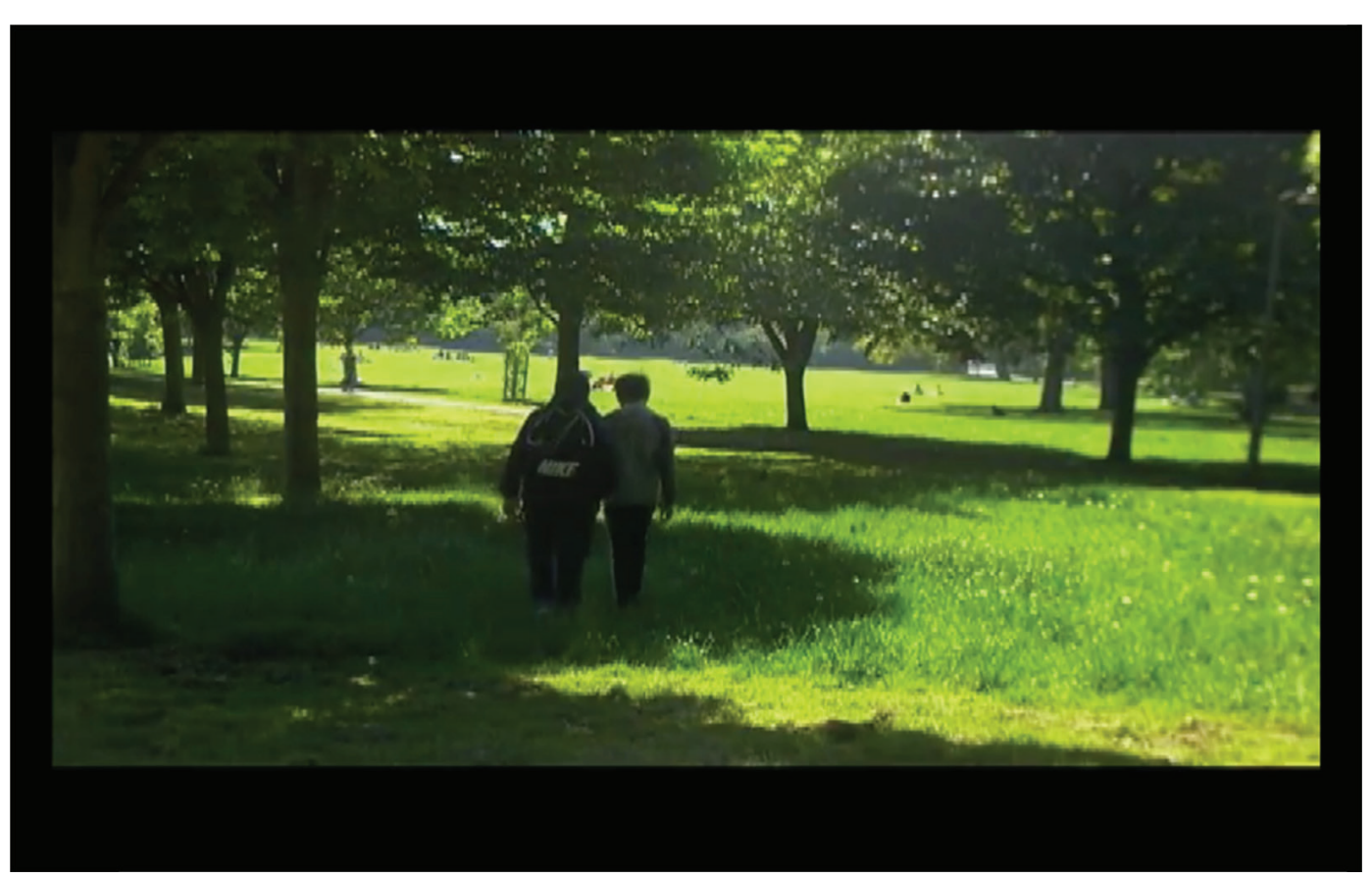

Figure 3: Beautiful images of a bleak future in Not Going Anywhere

While I do not regret these small, complementary tweaks, I do regret on impulse changing the name of the film without the children's approval from Off Track to Not Going Anywhere. Rewatching the film late in the process of reconstructing Arooba's edit, I noticed that the line 'He's not going anywhere' emerged powerfully from the first scene, in a manner that seemed to exert a greater resonance over the rest of the film than Off Track. In retrospect, I feel my intervention here went beyond appropriate co-creation, representing an authoritative, non-collaborative imposition on the film. I now wish I had factored in a greater degree of time in order to run the decision by Arooba, Josh, Ryan and their group.

\section{Undergraduate film productions}

Some years later, I found myself teaching on a production course in a British university, assisting undergraduate students making four-minute films. Here, for the first time, my students were marked (by me) on the work they were producing, and thus their production work was not made simply to explore the production process and develop expressive agency, but also formed a significant part of their undergraduate degrees. Aside from these crucial aspects, however, my process of assisting students through the production process as a university lecturer bore notable similarities to that I had employed with primary and secondary students with Understanding Cinema: I helped initially instigate development sessions, providing feedback, encouragement and criticism in response to ideas, before assisting students in realizing their films through script drafts and a series of edits of the films.

Early in my time working at undergraduate level, a student presented an idea for a short film in which various stories overlapped in a nightclub toilet, including a narrative involving what my students referred to initially as a 'looky looky woman', an unpaid bathroom attendant (usually an African expatriate) in nightclub toilets who offers club-goers access to luxury toiletries in return for tips. I advised that interlinking stories were probably too ambitious for a four-minute film, but that a film about a 'looky 
looky woman' might present a perspective I personally had not seen before on screen. I was also interested by the group's discomfort in talking about these workers, and was interested in the idea of someone on the fringes of the students' lives that they were aware of and yet knew little about. I made an intervention at this point to suggest that a film that tried to look sensitively at the experience of one such worker might be a valuable, topical project. I advised, however, that to approach such a topic sensitively, the group needed to commit to a sufficient degree of research to ensure they were not blithely misrepresenting the experience they were depicting. I also suggested that the students speak to colleagues within our department who could advise on the postcolonial sensitivities they should be aware of when conducting their research. The group rose to the challenge admirably, finding a number of expatriate workers who were willing to speak to them anonymously about their experiences. I helped the group think through their story, which they decided not to formally script in order to allow for improvisation, naturalistic performances and a feeling of verisimilitude.

I was not present for any aspect of the shoot, but subsequently met with the group to look through their rushes, and watched several successive cuts of the film, providing fairly detailed feedback both on a granular level about specific cuts and more globally about the shape and pacing of the film. Notably, I made a subsequent intervention after the first cut to suggest that the group attempt to reshoot some of the footage of the core encounter in the film, between the film's protagonist and a drunk club-goer that she finds passed out in a cubicle. I felt that this central interaction felt thin in the first cut of the film, in comparison with the ambient, environmental detail of the busy bathroom the group had captured very effectively. This central encounter felt lacking in coverage: the angles were few and did not cut together satisfactorily, the performances were a little unconvincing and under-directed, and in general the interaction was too quick. This is a recurring phenomenon I notice in student film work more generally: amid the busy chaos of a shoot (particularly those involving multiple extras), the focal drama of a scene is often lost or unfocused, and requires revisiting in reshoots. In the student project in question, this seemed an understandable, inevitable consequence of attempting to construct the competing registers of a naturalistically rendered, busy nightclub toilet alongside a quieter, more intimate dramatic interaction. I advised the group to attempt to revisit this aspect of the film with a greater degree of focus and concentration, which they did, reshooting the encounter with a noted degree of diligence and care. Ultimately, aided by an accomplished edit, sensitive performances and strong direction, the resulting film was - in my opinion - exceptional by the standards of an undergraduate student project shot within one term, and I accordingly awarded the film a high mark.

As a co-creator within this context, my role was similar once again to that of a 'creative producer': I assisted with the development of the idea, and at certain junctures made interventions in order to suggest that the students take a particular course of action. There is, however, a significantly greater degree of student agency in the process than there is within a film production in a primary school: all the practical work took place without any interaction from me, and - as an interlocutor in the process - I served as a remote commentator, whose advice the students had the choice to either follow or ignore.

\section{Postgraduate film productions}

The differences between the co-creative input I have when supervising student film production at undergraduate and postgraduate levels is relatively small. The scale and impact of the production is greater at postgraduate level: the films are usually longer, 
the marks more significant and there is a greater expectation of students about how the films will interact with the outside world, through film festivals and so on. While there remains - in my experience at least - a significant level of co-creation at postgraduate level, it is notable that I feel the need to write with a greater degree of anonymity here in fear that too great a degree of candour might somehow endanger my students' degrees. While this is paranoia, perhaps, discussions of co-creation seem much more fraught when marks and accusations of plagiarism are at stake. Student work in this context is not only marked, but marked by me, someone who - to a certain extent - has a co-creative influence on the film. Recalling discussions of the difficulty of marking or assessing creative work (an ongoing conversation within higher education institutions and beyond - see Rosenfeld Halverson et al., 2014: 388), there are certain oddities in a situation where, as a lecturer in film production, students choose whether to respond to my feedback on their productions, but are then marked by me. Is it the case that students who follow my feedback achieve higher marks? In my experience, sometimes, but not always. While all summative assessment in higher education is moderated by both internal and external examiners, would it be fairer if student work were core marked by someone other than the lecturer supervising them through the production process? I would say, yes and no: while in theory, films able to realize a certain level of ambition and accomplishment should be able to communicate to those without core knowledge of the production, it is also my experience that, no matter how rigorous the learning outcomes and marking criteria, there remains a certain, inescapable degree of subjectivity and personal taste when marking practical work. In this respect, it would seem unfair for students to be working towards one set of expectations, before being marked by another.

Given these sensitivities, I present here a series of decontexualized anecdotes of co-creation within a postgraduate context, rather than a full case study.

On a recent master's dissertation project, I made a series of interventions when assisting the film production of a student who was working in a fairly isolated manner, without access to other contributors. Sensing that the film-maker (an overseas student relatively unfamiliar with the city in which they were working) seemed somewhat isolated, I attempted to increase the affordances available to them, making perhaps a greater co-creative contribution than I would have done for students in the same year who were able to command a greater degree of collaborator support.

Elsewhere, another student, shooting a drama, shared with me a rough cut where I felt again that various core aspects of coverage had been missed within an ambitious production involving various significant aspects of production design. In particular, I felt that the film was missing close-up and reaction shots of its main character, and that most of the rushes consisted of mid-shots and wide shots (perhaps understandably, as these shots showcased the film's accomplished production design). I subsequently made a relatively insistent intervention to the student, arguing that the quality of their film would be raised significantly if they were able to perform reshoots. The student chose to follow my advice, allowing them to construct what was, from my perspective, a much more compelling sense of shot design in many of their scenes, which now placed the experience of the main character at the core of the film.

Elsewhere still, one of my students returned from an overseas shoot having shot a series of visually accomplished dramatic scenes that, because of a rushed, ambitious shoot, were all shot too fast for a project otherwise requiring a slow, lyrical pace. Reshoots were not an option, so I therefore suggested that the student make a virtue out of the limitation imposed by the footage, and for it to become part of the aesthetic 
strategy of the film that these scenes be pitched into slow motion. The director chose to follow this suggestion.

I had a significant degree of input into the casting process for another of my recent postgraduate students. The student would share with me filmed videos of their auditions, and I would provide relatively extensive comments by email, at times advising one choice over another. In terms of the two main roles, the student agreed with my preference for one of their choices, but disagreed with another. Here, similar to the relationship between a producer and a director, I presented opinions and advice, and my student chose where to follow my guidance and where to follow their own instincts.

Elsewhere, a student of mine found themselves in a situation where, for reasons beyond their control, they were unable to conduct an interview with their sister, who lived in a different country and was struggling to obtain a visa for travel. The interview was a core aspect of the film, which would have a formative influence on the subsequent shape of the edit (which could not begin until the interview had taken place). These logistical difficulties emerged at a key point in the production process when there was very little time left until the portfolio submission deadline. Attempting and failing to organize a deadline extension for the film, my student found themselves in a position where they needed to shoot a core part of their film faster than was physically and geographically possible. I therefore intervened to suggest the student film the interview via Skype, and - similar to the anecdote above - have this limitation inform the style of the film. As the sense of distance between the film-maker and their sister was one of the core themes of the film, it seemed interesting and provocative for the interview to appear via Skype. Again, this was a suggestion that my student chose to accept.

Speaking more broadly, it is notable that my working relationships with some of my master's students outlives the courses of study described here, and I continue to serve an advisory, producer-like role with particular students within their ongoing work. Just as I have stayed in touch with my mentor from the London Film School (mentioned above), and continue to ask their advice in both formal and informal contexts regarding my ongoing work as a film-maker, so I have stayed in touch with certain students as part of an ongoing, informal course of mentorship. In this way, once again, there can be said to be an ongoing continuum between film education and wider film culture, where the discursive, dialogical and intensely social processes in which films are developed begins at primary level, developing throughout a student's educational career with decreasing paternalistic scaffolding, before blending relatively seamlessly into film production outside educational environments.

\section{Conclusion}

As I hope this article serves to demonstrate, co-creation within student film production can take a multitude of forms, dependent on the relative autonomy of the learners. At primary level, in particular, the ecology of a given project - as defined by the availability of equipment, the amount of contact time and so on - has a direct effect on how much of the complex, multimodal and multi-craft process of film production one is able to open up to students. Where project ecology is able to generate sufficient affordances, students are able to shoot and edit their films with relatively little adult input. In contrast, where a project is unable to generate such affordances, I have found myself needing to intervene in the production to prop up aspects of the film-making process that I do not have the time or resources to open up to the students. 
Within undergraduate and postgraduate productions, the agency of film education practitioners within the film-making process inevitably decreases in inverse proportion with increasing student autonomy, and discussions of co-creation become increasingly fraught amid understandable concerns about plagiarism when student film projects are marked as part of degree portfolios, frequently by the film education practitioners assisting them co-creatively in the process. Nonetheless, co-creation remains just as present within student film-making in university environments as it is within primary and secondary schools, and I would argue that film education at university level can only benefit from healthy, non-defensive discussions about co-creation. Here I have dipped a toe in the water, and I hope that others will follow suit. While co-creation may take different forms at undergraduate and postgraduate level, film education practitioners continue to have a formative effect on student production in the feedback they provide on scripts, pre-production and the editing process. Once again, it is illuminating here to draw parallels between film education practitioners and creative producers, and doing so allows us to locate student film productions within a wider dialogical continuum within film culture, whereby films - as complex, multimodal entities constructed by multiple, intersecting crafts - are always the product of a diverse quorum of interlocutors, some junior and some senior, some emphasized as authors and others positioned as collaborators and co-creators, others remaining invisible.

One difficulty, perhaps, with these conclusions is the relatively unchallenged emphasis on a teleological process towards 'good work'. Who, ultimately, is the audience for student film productions, and by what value structures should student work be judged? (Rosenfeld Halverson et al., 2014). Reflecting upon the case studies above, and upon my career as a film education practitioner to date, I wonder if I have sometimes not allowed sufficient scope for my students to fail, and whether the dialogical struggle to make 'good films' is in itself sometimes a little inhibitive to learner agency and - as such - to student voice. A colleague of mine recently remarked to some of our postgraduate students that she would rather they made big, awkward films that were failures and yet explored something interesting or personal to them, rather than a 'good film' that trod an established path onwards to festivals. It can be difficult, within educational environments, to detach oneself from a fundamental sense of teleology, of striving towards something that has to be successful, functional and 'good'. I have frequently been told that, as a project, Understanding Cinema is about the process of making a film rather than final products. Yet, in a process incentivized by end-of-year screenings, a certain emphasis on final products cannot help but creep in. Further, it is a worldly yet unpleasantly real consideration that, as a result of a precarious economic landscape, work for film education practitioners is currently very thin on the ground. Within this context, it can be difficult not to feel one is, to an extent, judged on the quality of the student work one is assisting as a film education practitioner, and here a further danger of adult imposition creeps in. Once again, the ideals of student voice, self-efficacy and 'process not product' are pursued in a worldly context mediated by highly partial teachers and the underlying paucity of resources for arts-based education in the United Kingdom. Ultimately, perhaps - and here I reach beyond the scope of this article - we must ask difficult questions of the fundamental goals and pedagogical philosophy underlying any given programme of film education: is the goal producing 'good' work (to the extent that a sense of what is 'good' can be shared by both those running a project and those experiencing it as students), or is it enabling students to freely explore what is important to them, with a significant degree of independence from adult mediators and interlocutors? To what extent are those two goals antithetical to each other? As I have written elsewhere (Chambers, 2018), 
I do not believe they necessarily have to be, yet there exists a real possibility that they might become so.

Nevertheless, it remains my contention that film education can be, and in my experience is, part of an ongoing continuum of film culture whereby films are shaped wherever they fall within learners' careers - as part of a dialogical, dialectical process. At the London Film School, 25-year-old MA students engage with script consultations and edit viewings where their ideas and decisions are evaluated, judged and criticized, as they will be later within professional productions. Rewinding to the classroom-based work I have overseen in Scottish primary schools, that work is not so dissimilar: some voices remain more prioritized than others, yet the context is resolutely social. It would seem somewhat absurd to argue that those learning the complex, multimodal process of film-making must achieve a purity of 'voice' and autonomy in their work that it would be impossible to claim for professional film-makers. Recalling Jameson's notion of the 'prison-house of language' (1972), it would seem from one perspective that there is no such thing as 'authentic voice', if authentic voice consists of speech acts that solely articulate the self. As Mikhail Bakhtin (1990) has argued, each and every utterance must negotiate words and cultural matter soaked through with social and historical meaning, with predetermined inflection and orientation. Orner (1992: 8) argues that 'it is an illusion to believe that we can ever be fully present in speaking or writing, because using language entails using signs that are "half ours and half someone else's" (Bakhtin, 1981, p.345)'. One might equally recall Adorno (2004) here, whose theory of aesthetics argues that - as art contains society within its materials - so is every artistic production, no matter how abstract, a dialectical negotiation with wider society. So, in a proximate sense, might every individual attempt at 'auteurship' be seen as a complex social engagement, entangling the individual and the collective. It would seem highly understandable that there are frequently attempts within the discourses of film education to 'frame out' off-screen adult collaborators in placing the 'authentic voice' of the student centre-frame. And yet, I wonder if, in developing theories of film education that aim to be productive, progressive and - above all - useful, it might be worth exploring what actually happens within film education projects performed under the flag of 'authentic voice' in order to explore how that authentic voice might be better pursued.

\title{
Notes on the contributor
}

Jamie Chambers is a lecturer in Film and TV at Edinburgh College of Art. He is the founding editor of the Film Education Journal and has worked as a film education practitioner with Understanding Cinema and 'Cinéma, cent ans de jeunesse' since 2013. He is the curator of the Folk Film Gathering (the world's first folk film festival (www.folkfilmgathering.com)) and is the director of the award-winning, BAFTAnominated films When the Song Dies (2012) and Blackbird (2013).

\section{Filmography}

\author{
Au revoir les enfants (FR/DE/IT 1987, Louis Malle) \\ The Borrowers (GB/US 1997, Peter Hewitt) \\ Hamlet (GB/US 1996, Kenneth Branagh) \\ Jean de Florette (CH/FR/IT 1986, Claude Berri) \\ Rasputin (US/HU 1996, Uli Edel) \\ Santa Claus: The Movie (GB/US 1985, Jeannot Szwarc) \\ Twelfth Night (IE/GB/US 1996, Trevor Nunn)
}




\section{References}

Adorno, T.W. (2004) Aesthetic Theory. Trans. Hullot-Kentor, R. London: Continuum.

Aidelman, N. and Colell, L. (2018) 'Transmitting cinema: Some proposals for our time'. Film Education Journal, 1 (2), 147-62.

Bachmann, A. and Zahn, M. (2018) 'Film education as a multiplicity of practices: A media-ecological perspective'. Film Education Journal, 1 (1), 78-89.

Bakhtin, M.M. (1990) 'Discourse in the novel'. In Bakhtin, M.M. The Dialogic Imagination: Four essays. Ed. Holquist, M. Trans. Emerson, C. and Holquist, M. Austin: University of Texas Press, 259-422.

Bergala, A. (2016) The Cinema Hypothesis: Teaching cinema in the classroom and beyond (FilmmuseumSynemaPublikationen 28). Trans. Whittle, M. Vienna: Austrian Film Museum.

Buckingham, D. (2003) Media Education: Literacy, learning and contemporary culture. Cambridge: Polity Press.

Burn, A. (2018) 'Reflections on The Cinema Hypothesis: A response to Alain Bergala'. Film Education Journal, 1 (1), 51-63.

Chambers, J. (2018) 'Towards an open cinema: Revisiting Alain Bergala's The Cinema Hypothesis within a global field of film education'. Film Education Journal, 1 (1), 35-50.

Chambers, J. (forthcoming) '"We know what it's actually like": Voice, dialect and self-efficacy in Scotland's Understanding Cinema project'. In Lury, K. (ed.) The Child and Film. BFI/Bloomsbury.

Donnelly, A., Whelan, A. and Chambers, J. (2018) 'See You Tomorrow: A case study of the Understanding Cinema project at Granton Primary School in Edinburgh'. Film Education Journal, $1(1), 64-77$.

Gibbs, A. (2018) 'Film education otherwise: A response to Bergala's dialectics of cinema and schooling'. Film Education Journal, 1 (1), 90-100.

Henzler, B. (2018) 'Education à l'image and Medienkompetenz: On the discourses and practices of film education in France and Germany'. Film Education Journal, 1 (1), 16-34.

Jameson, F. (1972) The Prison-House of Language: A critical account of structuralism and Russian formalism. Princeton: Princeton University Press

Orner, M. (1992) 'Interrupting the calls for student voice in "liberatory" education: A feminist poststructuralist perspective'. In Luke, C. and Gore, J. (eds) Feminisms and Critical Pedagogy. New York: Routledge, 74-89.

Pinkerton, N. (2017) 'The Cinema Hypothesis: Teaching cinema in the classroom and beyond by Alain Bergala, translated by Madeline Whittle' (Review). Sight and Sound, 27 (2), 105.

Rosenfeld Halverson, E., Gibbons, D., Copeland, S., Andrews, A., Hernando Llorens, B. and Bass, M.B. (2014) 'What makes a youth-produced film good? The youth audience perspective'. Learning, Media and Technology, 39 (3), 386-403.

Rosenfeld Halverson, E., Lowenhaupt, R., Gibbons, D. and Bass, M. (2009) 'Conceptualizing identity in youth media arts organizations: A comparative case study'. E-Learning, 6 (1), 23-42.

Vygotsky, L.S. (1978) Mind in Society: The development of higher psychological processes. Ed. Cole, M. Cambridge, MA: Harvard University Press.

Willett, R., Burn, A. and Buckingham, D. (2005) 'New media, production practices, learning spaces'. Education, Communication and Information, 5 (1), 1-3. 